\title{
Hypofractionated radiotherapy as a salvage treatment for recurrent hepatocellular carcinoma with inferior vena cava/right atrium tumor thrombus: a multi-center analysis
}

Jinrong Lou ${ }^{1+} \mathbb{D}_{\text {, Yong } \mathrm{Li}^{2+} \text {, Kangning Liang }}^{2}$, Yutian Guo ${ }^{2}$, Changlong Song ${ }^{3}$, Lei Chen², Lifang Wang ${ }^{1}$, Fei Wang ${ }^{1}$, Li Zhang ${ }^{1}$, Xia Chen ${ }^{1}$, Xiangdong $\mathrm{Xu}^{1^{*}}$ and Mianshun $\mathrm{Pan}^{2^{2 *}}$

\begin{abstract}
Background: Recurrent hepatocellular carcinoma (HCC) with a tumor thrombus (TT) extending into the inferior vena cava (IVC)/right atrium (RA) is generally regarded as a terminal-stage condition and there is no worldwide consensus on the proper management of this situation. In the present study, we report the efficacy of hypofractionated radiotherapy (HFRT) as a salvage treatment for recurrent HCC with IVC/RA TT.

Methods: We retrospectively reviewed 75 HCC patients with an IVC/RA TT who were referred for HFRT at three institutions between 2008 and 2016.57 cases had a TT located in the IVC (IVC group), and 18 cases had a TT located in the IVC and RA (IVC + RA group). HFRT was designed to focus on the $T$ with or without the primary intrahepatic tumors.

Results: In all cases, the $\Pi$ completely disappeared (CR) in 17 patients (22.7\%), 55 patients (73.3\%) had a partial response $(\mathrm{PR})$, and 3 patients (4.0\%) had a stable disease (SD). There were no cases of progressive disease (PD). The 1-, 2-, and 3year overall survival rates of the 75 patients were 38.7\% (29/75), 13.3\% (10/75) and 5.3\% (4/75), respectively. The overall median survival time was 10 months. The mean survival times for the IVC group and IVC+ RA group were $13.8 \pm 1.1$ and $11.6 \pm 2.5$ months, respectively. There was no significant difference in survival between the two groups $(p=0.205)$. Logrank test revealed that factors predicting poor survival were Child-Pugh B liver function classification, AFP $\geq 400 \mu \mathrm{g} / \mathrm{L}$, intrahepatic multiple tumors, distant metastases, only the $\Pi$ as the target, a biological effective dose (BED) < 55 Gy and no chance of further radiotherapy.
\end{abstract}

Conclusions: HFRT appears to be an effective and reasonable treatment option for recurrent HCC patients with IVC/RA $\pi$. The location of the tumor thrombus, either in IVC or in IVC and RA, is not the factor that influences the efficacy of radiotherapy or survival.

Keywords: Hepatocellular carcinoma, Inferior vena cava, Right atrium, Tumor thrombus, Hypofractionated radiotherapy

\footnotetext{
* Correspondence: xuxiangdong8416@163.com; panmianshun@126.com

†Jinrong Lou and Yong Li are contributed equally to this study and share the

firstauthorship

${ }^{1}$ Department of Cardiology, Jiading District Central Hospital Affiliated

Shanghai University of Medicine and Health Sciences, 1 Chengbei Road,

Shanghai 201800, China

${ }^{2}$ Center of Radiation Oncology, Wujing Hospital, 380 Hongxu Road, Shanghai

201103, China

Full list of author information is available at the end of the article
}

(c) The Author(s). 2019 Open Access This article is distributed under the terms of the Creative Commons Attribution 4.0 International License (http://creativecommons.org/licenses/by/4.0/), which permits unrestricted use, distribution, and reproduction in any medium, provided you give appropriate credit to the original author(s) and the source, provide a link to the Creative Commons license, and indicate if changes were made. The Creative Commons Public Domain Dedication waiver (http://creativecommons.org/publicdomain/zero/1.0/) applies to the data made available in this article, unless otherwise stated. 


\section{Background}

Large vascular invasion is a common feature of recurrent hepatocellular carcinoma (HCC). The presence of portal vein (PV) or hepatic vein tumor thrombus (TT) is frequent in these patients [1]. TT can progress along the venous wall to the inferior vena cava (IVC) or even to the right atrium (RA) [1, 2]. IVC/RA TT is found in 3$4 \%$ of HCC patients, but it seems to be increasingly discovered as a result of longer survival of HCC patients and advances in imaging techniques [3-5]. This situation may result in distant metastasis, pulmonary embolism or cardiac outflow tract obstruction, so the prognosis is usually extremely poor, and the median survival is only 1.9 months [6], which is worse than that of patients with a PV TT [7-9]. As such, the IVC/RA TT should be removed as soon as possible [10].

Although surgical removal of a TT may be effective, it is rarely performed because of the limited normal hepatic volume and higher surgery risk in these recurrent HCC patients [2-9]. Some selected patients can choose transarterial chemoembolization (TACE), but they always got unsatisfactory effect and severe complications $[3,11,12]$. In the present study, we report the efficacy of hypofractionated radiotherapy (HFRT) as a salvage treatment for recurrent hepatocellular carcinoma with IVC/ RA TT.

\section{Methods}

\section{Patients and diagnoses}

Between January 2008 and May 2016, 1897 patients underwent HFRT for HCC at the Center of Radiation Oncology of Shanghai Wujing Hospital, Guangdong Nongken Tumor Hospital and Shanghai Jiading Central Hospital. Of these, 104 patients (5.5\%) were diagnosed with advanced HCC with IVC/RA TT. There were 78 cases (4.1\%) with TT located in the IVC and 26 cases (1.4\%) with TT located in both the IVC and RA. Among them, 75 cases were recurrent $\mathrm{HCC}$ patients who received at least one definitive treatment for intrahepatic primary tumors and had complete follow-up imaging and data. Prior treatments included surgical resection, TACE, radiofrequency, radiotherapy and sorafenib. HCC was diagnosed by histopathological examination or typical manifestations in imaging [13].

\section{Hypofractionated radiotherapy}

Hypofractionated radiotherapy was delivered by a stereotactic gamma-ray therapeutic system (SGS-I, Huiheng Medical, Shenzhen, China). A stereotactic frame and 18 $\mathrm{Co}^{60}$ sources in this system can deliver a high-precision radiotherapy on the target volume [14]. Each patient was immobilized by a vacuum bag and underwent 2 phases of enhanced CT simulation under a normal breathing situation with a $5 \mathrm{~mm}$ CT-slide thickness. This 2-phase scan had an initial interval of $2.5 \mathrm{~mm}$. The 2-phase images were fused into the planning system with the CT-slide thickness of $2.5 \mathrm{~mm}$, accounting for tumor motion. The gross tumor volume (GTV) was defined by the hyperdense area of the intrahepatic primary tumor during the arterial phase and/or the hypodense filling defect area of the tumor thrombus during the venous phase. The clinical target volume (CTV) expanded the GTVs of the primary tumors and tumor thrombus by a margin of $5 \mathrm{~mm}$ and $0 \mathrm{~mm}$, respectively. A margin of 5 $\mathrm{mm}$ to the CTV was inclued in the planning target volume (PTV). Taking into account the size of the tumor and the patient's liver function, radiotherapy was designed to target only the tumor thrombus in 29 patients and both the tumor thrombus and primary tumors in 46 patients. A dose of 3-4 Gy was delivered once a day and five times per week, with a total dose of 30-48 Gy (the median dose is 38Gy). The biological effective dose (BED) was evaluated by the equation: $B E D=$ nd $[1+\mathrm{d} /$ $(\alpha / \beta)$ ]. The mean $50 \%$ of the non-cancerous liver volume received a dose of $<25 \mathrm{~Gy}$, The $\mathrm{V}_{30}$ of the uninvolved heart was $<20 \%$. During radiotherapy, the patients underwent routine physical examinations and blood tests every week.

\section{Response evaluation and follow-up}

Due to the short survival of these patients and the risk of sudden death by tumor thromboembolism, the first follow-up visit was chosen to occur 0.5-1.0 months after completion of radiotherapy. At that visit, a response evaluation to the therapy was confirmed by Doppler ultrasound (Fig. 1). The CT/MRI scans were performed every 2-3 months during the first year and every 6 months thereafter (Fig. 2). The follow-up period ranged from 3 to 40 months (median, 12 months). Follow-up evaluations consisted of physical examinations, blood tests for tumor markers, liver function tests and complete blood cell count. Myocardial enzymes were detected in patients with RA tumor thrombus.

Based on CT/MRI imaging, local tumor control was classified as complete response (CR) that is complete disappearance of all measurable lesions; partial response (PR) that is $50 \%$ reduction in the sum of the perpendicular diameters of all measurable lesions; progressive disease (PD) that is $25 \%$ increase in the sum of the perpendicular diameters of all measurable lesions or the development of new lesions; Patients whose disease did not meet the criteria for either a PR or PD were classified as having stable disease (SD). Objective response rate (ORR) was defined to include those patients with $\mathrm{CR}$ and PR.

\section{Statistical analysis}

The normality of each continuous variable was verified by the Kolmogorov Smirnov test and the variables were 

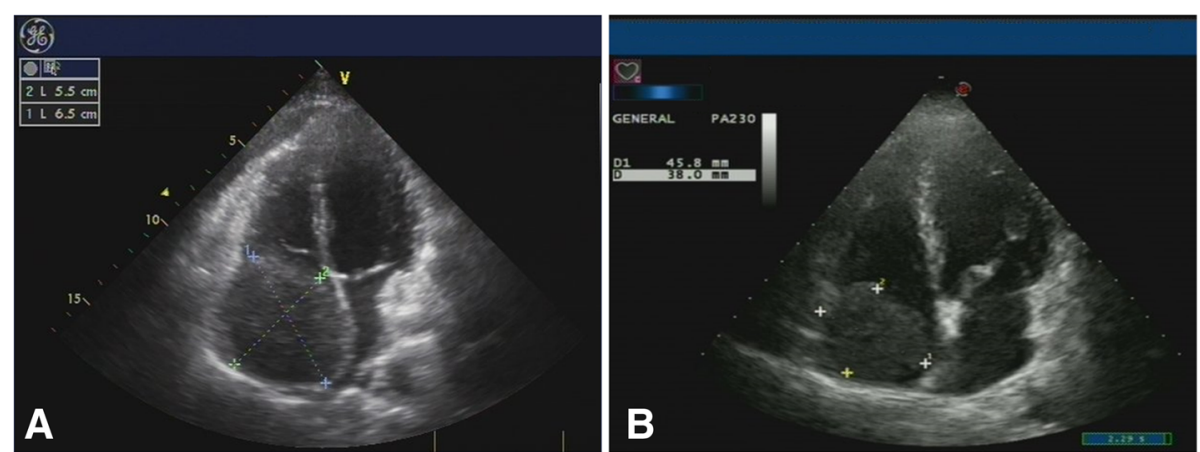

Fig. 1 Doppler ultrasound follow-up images of one RA $\Pi$ case. a Before HFRT, the $\Pi\left(5.5^{*} 6.5 \mathrm{~cm}\right)$ filled the right atrium. b 14 days after completion of RT, the $T\left(3.8^{*} 4.6 \mathrm{~cm}\right)$ was decreased in size

compared by an independent sample $t$-test. Categorical variables were compared either by chi-squared test or Fisher's Exact Test. Kaplan-Meier method was used for the survival analysis and statistical significance determined by the log-rank test. Statistical analysis was performed with SPSS 19.0 software (SPSS, Chicago, IL).

\section{Results}

\section{Population characteristics}

The patients' characteristics are showed in Table 1 . The ratio of men and women is.

66: 9 and the median age is 53.0 years (range, 23-75 years). 57 cases had a tumor thrombus located in the IVC (IVC group), and 18 cases had a tumor thrombus located in the IVC and RA (IVC + RA group). In total, 92.0\% patients had underlying chronic liver disease induced by hepatitis B virus infection. Most patients (77.3\%) had obvious symptoms including edema of lower extremity, abdominal pain and distention. The performance status (PS score) of the IVC group showed a slight advantage, but there was no significant difference between the two groups $(p=0.543)$. Because of major vascular invasion, all patients belonged to BCLC (Barcelona Clinic Liver Cancer staging) Stage C. In all cases, the tumor thrombus was contiguous with the intrahepatic primary tumors. The lymph node metastasis rate was $7.3 \%(7 / 75)$, and the distant metastasis rate was $28.0 \%$ $(21 / 75)$. The numbers of prior therapy for the intrahepatic primary tumors were $3.7 \pm 1.5$ and $4.1 \pm 1.7$ for IVC and IVC + RA group, respectively. There was no significant difference in the baseline characteristics between the two groups.

\section{Response to treatment}

At the end of the study, out of all the 75 patients who received $\mathrm{RT}$, the TT completely disappeared (CR) in 17 patients $(22.7 \%)$. In addition, 55 patients $(73.3 \%)$ had a PR, and 3 patients (4.0\%) had SD. No PD was found. The ORR was $96 \%$. Comparing the response rate for IVC vs. IVC + RA TT, the rate of CR, PR and SD were $26.3 \%(15 / 57)$ vs. $11.1 \%(2 / 18), 70.2 \%(40 / 57)$ vs. $83.3 \%$ $(15 / 18)$, and $3.5 \%(2 / 57)$ vs. $5.6 \%(1 / 18)$, respectively.

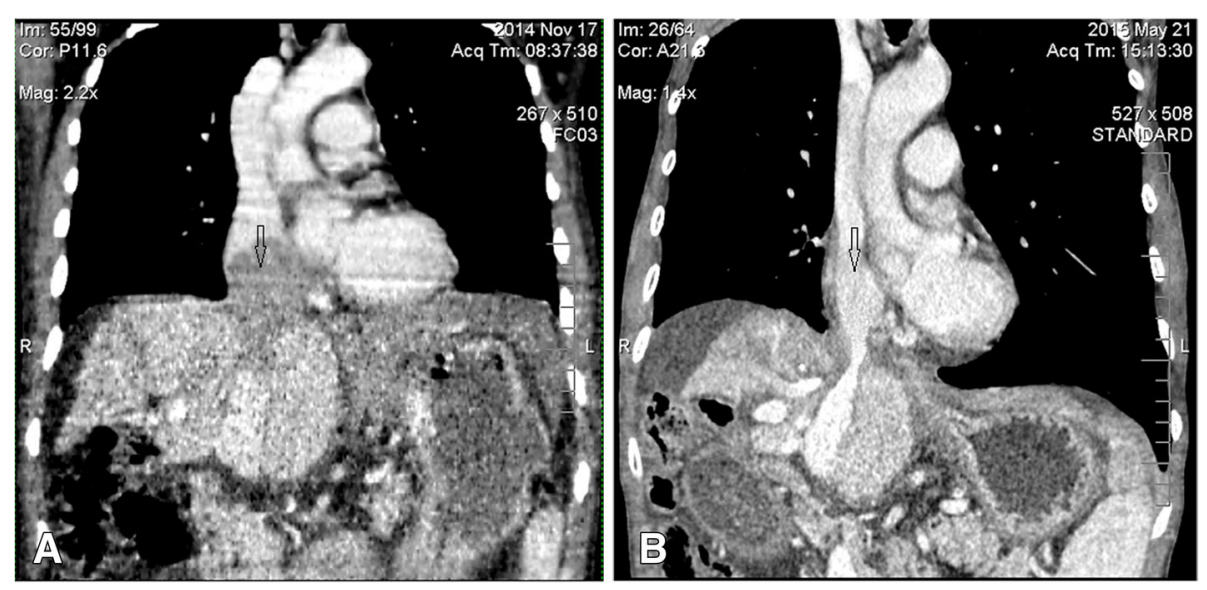

Fig. 2 Computed tomography (CT) follow-up images of one RA TT case. a Before HFRT, the $\pi\left(7.5^{*} 6.5 \mathrm{~cm}\right)$ filled the right atrium, resulting in circulatory disorders and cardiac enlargement. b 6 months after completion of RT, the $\pi$ disappeared and circulation returned to normal 
Table 1 The clinical characteristics of the two groups

\begin{tabular}{|c|c|c|c|}
\hline Variables & $\begin{array}{l}\text { IVC } \\
(n=57)\end{array}$ & $\begin{array}{l}\text { IVC + RA } \\
(n=18)\end{array}$ & $p$ \\
\hline Age (years) & $54.6 \pm 10.6$ & $51.9 \pm 10.3$ & 0.340 \\
\hline \multicolumn{4}{|l|}{ Gender } \\
\hline Male & $50(87.7 \%)$ & $16(88.9 \%)$ & \multirow[t]{2}{*}{0.631} \\
\hline Female & $7(12.3 \%)$ & $2(11.1 \%)$ & \\
\hline \multicolumn{4}{|l|}{ Performance status } \\
\hline 0 & $14(24.6 \%)$ & $3(16.7 \%)$ & \multirow[t]{2}{*}{0.543} \\
\hline 1 & $43(75.4 \%)$ & $15(83.3 \%)$ & \\
\hline \multicolumn{4}{|l|}{ Child-Pugh classification } \\
\hline A & $51(89.5 \%)$ & $15(83.3 \%)$ & \multirow[t]{2}{*}{0.678} \\
\hline B & $6(10.5 \%)$ & $3(16.7 \%)$ & \\
\hline \multicolumn{4}{|c|}{ Intrahepatic tumor number } \\
\hline Solitary & $43(75.4 \%)$ & $11(61.1 \%)$ & \multirow[t]{2}{*}{0.238} \\
\hline Multiple & $14(24.6 \%)$ & 7 (38.9\%) & \\
\hline \multicolumn{4}{|l|}{ LN metastases } \\
\hline Absent & $53(93.0 \%)$ & $15(83.3 \%)$ & \multirow[t]{2}{*}{0.348} \\
\hline Present & $4(7.0 \%)$ & $3(16.7 \%)$ & \\
\hline \multicolumn{4}{|l|}{ Distant metastases } \\
\hline Absent & $44(77.2 \%)$ & $10(55.6 \%)$ & \multirow[t]{2}{*}{0.075} \\
\hline Present & $13(22.8 \%)$ & $8(44.4 \%)$ & \\
\hline \multicolumn{4}{|l|}{$\mathrm{HBsAg}$} \\
\hline Negative & $5(8.8 \%)$ & $1(5.6 \%)$ & \multirow[t]{2}{*}{0.555} \\
\hline Positive & $52(91.2 \%)$ & $17(94.4 \%)$ & \\
\hline \multicolumn{4}{|l|}{ AFP $(\mu \mathrm{g} / \mathrm{L})$} \\
\hline$<400$ & $31(54.4 \%)$ & $13(72.2 \%)$ & \multirow[t]{2}{*}{0.180} \\
\hline$\geq 400$ & $26(45.6 \%)$ & $5(27.8 \%)$ & \\
\hline No. of prior therapies & $3.7 \pm 1.5$ & $4.1 \pm 1.7$ & 0.407 \\
\hline
\end{tabular}

Abbreviations: IVC inferior vena cava, $R A$ right atrium, $L N$ lymphonodus, AFP a-fetoprotein

There was no significant difference between the two groups $(p=0.370)$. During the follow-up, all of the patients developed intrahepatic progression, 76.1\% (35/46) were within the radiation field and $23.9 \%$ (11/46) were other intrahepatic metastases. 37 cases had received further HFRT treatment (Table 2).

\section{Survival}

At the end of this study, 69 patients (92\%) had died, and 6 patients $(8 \%)$ were alive: 4 patients in the IVC TT group and 2 patients in the IVC + RA TT group. The causes of death included intrahepatic tumor progression in $60(87.0 \%)$ patients, esophageal varices bleeding in 5 (7.2\%) patients, brain metastases in $3(4.3 \%)$ patients, and brainstem hemorrhage in $1(1.4 \%)$ patient. The 1-, 2 -, and 3-year overall survival rates of the 75 patients were $38.7 \%(29 / 75), 13.3 \%(10 / 75)$ and $5.3 \%(4 / 75)$, respectively; the overall median survival time was 10
Table 2 Log-rank test for characteristics of survival in 75 patients

\begin{tabular}{|c|c|c|c|}
\hline Variables & $n$ & OS (mo) & $\begin{array}{l}\text { log-rank } \\
\text { test } \\
P \text { values }\end{array}$ \\
\hline \multicolumn{4}{|l|}{ Gender } \\
\hline Female & 9 & $\begin{array}{l}12.2 \pm \\
1.79\end{array}$ & 0.753 \\
\hline Male & 66 & $\begin{array}{l}13.4 \pm \\
1.15\end{array}$ & \\
\hline \multicolumn{4}{|l|}{ Age } \\
\hline$<50$ & 27 & $\begin{array}{l}12.5 \pm \\
1.43\end{array}$ & 0.613 \\
\hline$\geq 50$ & 48 & $\begin{array}{l}13.6 \pm \\
1.38\end{array}$ & \\
\hline \multicolumn{4}{|c|}{ Child-Pugh classification } \\
\hline A & 66 & $\begin{array}{l}13.9 \pm \\
1.09\end{array}$ & $<0.001$ \\
\hline B & 9 & $6.4 \pm 0.80$ & \\
\hline \multicolumn{4}{|c|}{ Performance status } \\
\hline 0 & 17 & $\begin{array}{l}14.3 \pm \\
2.39\end{array}$ & 0.728 \\
\hline 1 & 58 & $\begin{array}{l}12.9 \pm \\
1.11\end{array}$ & \\
\hline \multicolumn{4}{|l|}{$\mathrm{HBsAg}$} \\
\hline Negative & 6 & $\begin{array}{l}15.5 \pm \\
2.41\end{array}$ & 0.462 \\
\hline Positive & 69 & $\begin{array}{l}12.9 \pm \\
1.09\end{array}$ & \\
\hline \multicolumn{4}{|l|}{ AFP $(\mu \mathrm{g} / \mathrm{L})$} \\
\hline$<400$ & 44 & $\begin{array}{l}14.8 \pm \\
1.59\end{array}$ & 0.041 \\
\hline$\geq 400$ & 31 & $\begin{array}{l}10.9 \pm \\
0.92\end{array}$ & \\
\hline \multicolumn{4}{|c|}{ No. of prior therapies } \\
\hline$<4$ & 35 & $\begin{array}{l}12.8 \pm \\
1.43\end{array}$ & 0.648 \\
\hline$\geq 4$ & 40 & $13.6 \pm$ & \\
\hline
\end{tabular}

Intrahepatic tumor number

$\begin{array}{ccl}\text { Solitary } & 54 & 15.1 \pm \\ & & 1.25 \\ \text { Multiple } & 21 & 7.6 \pm 0.59 \\ \text { LN metastases } & & 13.6 \pm \\ \text { Absent } & 66 & 1.11 \\ & & 10.6 \pm \\ \text { Present } & 9 & 2.51\end{array}$

$<0.001$

Distant metastases

Absent

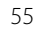

$14.7 \pm$

1.29

0.001

Present

20

$8.8 \pm 0.58$

PTV

TT

TT + PT

29

$7.6 \pm 0.61$

$<0.001$
$6.3=$

BED Dose (Gy) 
Table 2 Log-rank test for characteristics of survival in 75 patients (Continued)

\begin{tabular}{|c|c|c|c|}
\hline Variables & $n$ & OS (mo) & $\begin{array}{l}\text { log-rank } \\
\text { test } \\
P \text { values }\end{array}$ \\
\hline$<55$ & 43 & $\begin{array}{l}10.5 \pm \\
0.97\end{array}$ & 0.001 \\
\hline$\geq 55$ & 32 & $\begin{array}{l}16.6 \pm \\
1.76\end{array}$ & \\
\hline \multicolumn{4}{|c|}{ Further radiotherapy } \\
\hline Yes & 37 & $\begin{array}{l}17.3 \pm \\
1.58\end{array}$ & $<0.001$ \\
\hline No & 38 & $8.6 \pm 0.59$ & \\
\hline \multicolumn{4}{|c|}{ Thrombus location } \\
\hline IVC only & 57 & $\begin{array}{l}13.8 \pm \\
1.13\end{array}$ & 0.205 \\
\hline $\mathrm{IVC}+\mathrm{RA}$ & 18 & $\begin{array}{l}11.6 \pm \\
2.48\end{array}$ & \\
\hline
\end{tabular}

Abbreviations: OS overall survival, AFP a-fetoprotein, $L N$ lymphonodus, $T T$ tumor thrombus, $P T V$ planning target volume, $P T$ primary tumors, $B E D$ biological effective dose, IVC inferior vena cava, $R A$ right atrium

months. The survival for patients in IVC TT group was $43.9 \%(25 / 57)$ at 1 year, $14.0 \%(8 / 57)$ at 2 years, and $5.3 \%$ $(3 / 57)$ at 3 years, with a median survival time of 11 months; the longest survival was 40 months. The survival of patients in the IVC + RA TT group was $22.2 \%$ $(4 / 18)$ at 1 year, $11.1 \%(2 / 18)$ at 2 years, and $5.6 \%(1 / 18)$ at 3 years, with a median survival time of 8 months. The longest survival time was 38 months. The mean survival time for the IVC TT only group was $13.8 \pm 1.1$ months, and for the IVC + RA TT group was $11.6 \pm 2.5$ months. As shown in Fig. 3, the two groups did not have a significant difference in survival $(p=0.205)$.

Log-rank test revealed that higher $\alpha$-fetoprotein (AFP) level, Child-Pugh B liver function classification, multiple intrahepatic tumors, distant metastasis, only the TT in the PTV, BED < 55 Gy and no further radiotherapy were significantly associated with a worse prognosis. We noted that for the patients receiving $\mathrm{RT}$, the location of the tumor thrombus, either in IVC or in IVC + RA, did not influence the survival. If the PTV included the TT and primary tumor, the BED dose was at least 55 Gy or the patients had the chance to receive further radiotherapy, the mean survival time was more than 16 months (Table 2).

\section{Toxicity}

22 patients $(29.3 \%)$ suffered from transient acute upper gastrointestinal toxicities. According to the grading system of the Radiation Therapy Oncology Group, 18 patients were assessed as grade 1 and 4 patients were assessed as grade 2 . For the patients with a RA tumor thrombus, there was no significant increase in the myocardial enzymes after radiotherapy. Radiation-induced liver disease, pulmonary embolism or sudden cardiac arrest was not observed.

\section{Discussion}

Liver cancer is a commonly diagnosed cancer and second leading cause of cancer death worldwide in men and in less developed countries, with China alone accounting for approximate $50 \%$ of the total number of cases and deaths $[15,16]$.

HCC is the most common (70 to $85 \%$ ) histological type of primary liver cancer [17]. The treatment for this disease usually requires a multiple management strategy with different rewards and risks from each method [18]. Unfortunately, most patients are still suffering from tumor recurrence. When recurrent HCC does occur, the tumor tends to be more aggressive and harder to treat, and a hepatic/portal vein TT is very common [19]. However, a TT extending into the IVC/RA is reported only in 0.67 to $4.8 \%$ HCC patients [20-22]. In this study, the rates of IVC TT and IVC + RA TT were 5.5 and $1.4 \%$, similar to previous report. With further prolongation of survival time in $\mathrm{HCC}$ patients, the incidence of a TT is increasing.

$\mathrm{HCC}$ with an IVC/RA TT is generally regarded as a terminal-stage condition and there is no worldwide consensus on the proper management of this situation [23]. The 1-year survival rates of some palliative treatments such as chemotherapy, TACE and radiofrequency ablation range from 7 to $18 \%$ [24-26]. Although surgery has long been attempted for this situation, its therapeutic effect seems unsatisfactory [27]. Clinically, to guide surgical options, IVC and RA TT are usually classified into three types: type I when the IVC TT is below the diaphragm; type II when the IVC TT is above the diaphragm and under the atrium; and type III when the TT

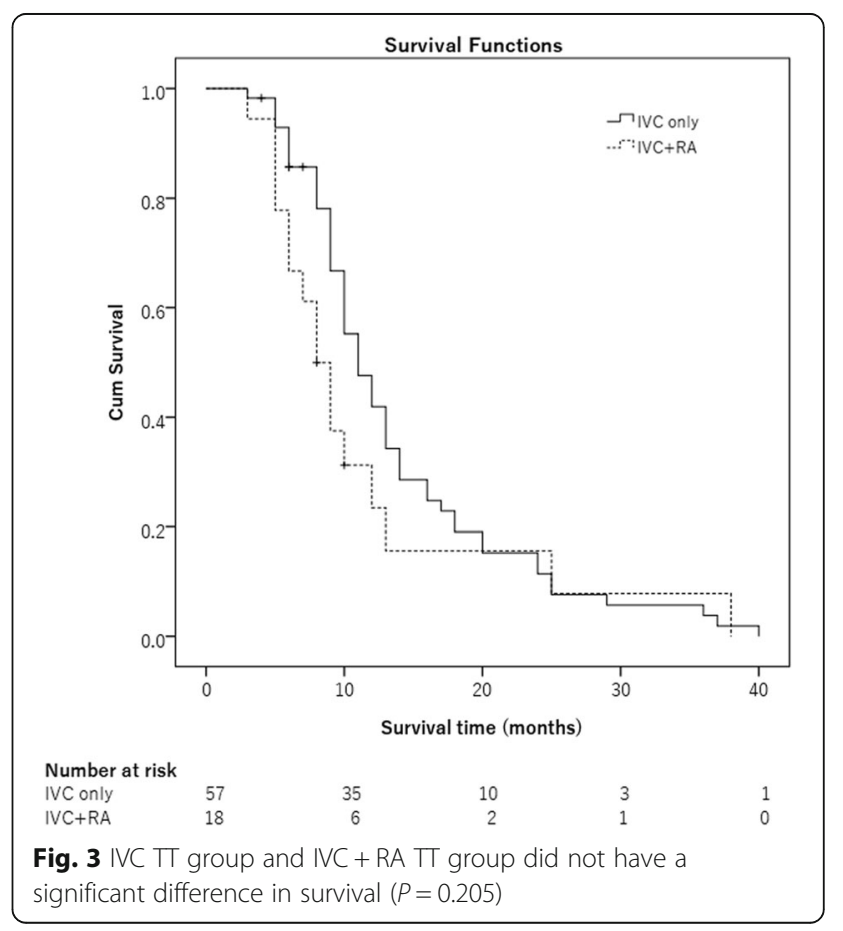


has entered into the right atrium. For type III, the operation should be performed by liver and cardiothoracic surgeons [28]. However, although underwent curative resection, the median recurrence-free survival of these patients was only 3.8 months [29]. Nevertheless, the initial operation can reduce the tumor burden quickly and offer these patients the chance for subsequent multidisciplinary treatments, such as TACE, radiotherapy, local ablation and so on, which may help reduce tumor recurrence and improve survival time [27].

Radiotherapy is a very important treatment for liver cancer. Modern radiation techniques have greatly reduced the risk of radiation-associated disease by delivering a high dose to the target, with a sharp dose gradient to the adjacent normal tissues [30,31]. Clinical outcomes of radiotherapy for $\mathrm{HCC}$ TT are encouraging and patients with an isolated IVC TT may have significant higher response rates and longer survival compared to those with a PV TT [12]. Radiotherapy may be of a strongly protective factor and help to prolong survival of HCC patients with TT [32].

Because of the low incidence, the clinical outcomes of RT for IVC and RA tumor thrombus are rarely reported. Duan [33] ever reported that a combination of radiotherapy and TACE was more effective in the control of HCC IVC/RA TT and no obviously severe complications. In our study, all the cases were recurrent HCC. Overall, 94.6\% (71/75) of cases received TACE. Unfortunately, in each case, tumor thrombus was still in progress. After salvage radiotherapy, the ORRs were 96.5\% (55/57) and 94.4\% (17/18) for IVC and IVC + RA tumor thrombosis, respectively. No PD cases were found. The median survival times were 11 and 8 months for patients in the IVC and IVC + RA tumor thrombosis groups, respectively. There was no significant difference in survival $(p=0.205)$. The location of the tumor thrombus, for either in IVC or in IVC + RA, did not influence survival. Log-rank test revealed that AFP $\geq 400 \mu \mathrm{g} / \mathrm{L}$, Child-Pugh $B$ liver function, multiple intrahepatic tumors, distant metastasis, only the TT in the PTV, BED $<55$ Gy and no further radiotherapy were found to be significantly associated with a worse prognosis. However, when the PTV included the TT and primary tumor, the BED dose was at least $55 \mathrm{~Gy}$ or the patients had the chance to receive further radiotherapy, the mean survival time was more than 16 months.

Although there is a risk of thrombus dislodgment, we never encountered this during radiotherapy. One reason may be that the tumor thrombus was covered by endothelium and subsequently adherent to the wall of the IVC or the endocardium [20]. Another reason may be that the tumor thrombus was a contiguous extension of the intrahepatic HCC. Finally, the TT is frequently supplied by the hepatic artery and some extrahepatic arteries [3-33], these blood vessels may serve as a "tree root" and stabilize the TT.

The limitations of this study include its small number of patients and the absence of liver function index of retention rate of indocyanine green 15 min after administration (ICGR15) because of its retrospective design. In addition, the late toxicity was difficult to assess because of the short survival time of these patients. Although with these deficiencies, HFRT appears to be a reasonable treatment for recurrent HCC patients with IVC/RA tumor thrombus due to its high efficacy and low toxicity. However, the question of why IVC/RA TT is a radiation sensitive lesion still needs further study.

\section{Conclusions}

In summary, HFRT appears to be an effective and reasonable treatment option for recurrent $\mathrm{HCC}$ patients with IVC/RA TT. Patients with Child-Pugh classification A, a PTV including the TT and primary tumor, a delivered BED dose $\geq 55$ Gy and the opportunity to receive further radiotherapy may obtain a survival benefit. The location of the tumor thrombus was not a factor that influenced the efficacy of radiotherapy or survival.

\section{Abbreviations \\ 3D-CRT: Three-dimensional conformal radiotherapy; AFP: a-fetoprotein; BED: Biological effective dose; CPB: Cardiopulmonary bypass; CR: Completely disappeared; CT: Computed tomography; CTV: Clinical target volume; GTV: Gross tumor volume; HCC: Hepatocellular carcinoma; HFRT: Hypofractionated radiotherapy; ICGR15: Retention rate of indocyanine green 15 min after administration; IMRT: Intensity modulated radiotherapy; IVC: Inferior vena cava; MRI: Magnetic resonance imaging; OS: Overall survival; PD: Progressive disease; PET: Positron emission tomography; PR: Partial response; PTV: Planning target volume; PV: Portal vein; RA: Right atrium; SD: Stable disease; TACE: Transarterial chemoembolization; TT: Tumor thrombus}

\section{Acknowledgements}

We thank Dr. Yu Gan for his contribution to statistical analysis and thank Dr. Yongsong Guan, Dr. Hideo Baba, Dr. Huang Zhu, Dr. Anthony D. Elias and Dr. Adam Garsa for their very valuable suggestions.

\section{Authors' contributions}

MSP, XDX, JRL and $Y L$ set up the study design and study protocols. JRL, YL, $K N L, Y T G, C L S, L C, L F W, F W, L Z$ and XC participated in performing the research. JRL and $Y L$ drafted the manuscript. All authors reviewed and approved the final manuscript.

\section{Funding}

This work was funded by the 13th Five-Year National Key Research and Development Plan Project (2017YFC0113700) and Shanghai Jiading Medical Foundation (TSO2) that have no role in the collection, analysis, interpretation of results or writing of the manuscripts.

Availability of data and materials

Additional data and materials may be requested from the corresponding author on reasonable request.

\section{Ethics approval and consent to participate}

This study was approved by the ethics committees of Shanghai Wujing Hospital, Shanghai Jiading Central Hospital and Guangdong Nongken Central Hospital (WJN-HZO1). Written informed consent is obtained from patients or their immediate family. 


\section{Consent for publication}

Not applicable.

\section{Competing interests}

The authors declare that they have no competing interests.

\section{Author details}

'Department of Cardiology, Jiading District Central Hospital Affiliated Shanghai University of Medicine and Health Sciences, 1 Chengbei Road, Shanghai 201800, China. ${ }^{2}$ Center of Radiation Oncology, Wujing Hospital, 380 Hongxu Road, Shanghai 201103 , China. ${ }^{3}$ Center of Radiation Oncology, Guangdong Nongken Central Hospital, 2 Renmin Road, Guangzhou 524002, China

Received: 16 September 2018 Accepted: 24 June 2019

Published online: 05 July 2019

\section{References}

1. Okuda K. Hepatocellular carcinoma: clinicopathological aspects. J Gastroenterol Hepatol. 1997;12(9-10):S314-8.

2. Okada S. How to manage hepatic vein tumour thrombus in hepatocellular carcinoma. J Gastroenterol Hepatol. 2000;15(4):346-8.

3. Lee IJ, Chung JW, Kim HC, Yin YH, So YH, Jeon UB, Jae HJ, Cho BH, Park JH. Extrahepatic collateral artery supply to the tumor thrombi of hepatocellular carcinoma invading inferior vena cava: the prevalence and determinant factors. J Vasc Interv Radiol. 2009;20(1):22-9.

4. Chang JY, Ka WS, Chao TY, Liu TW, Chuang TR, Chen LT. Hepatocellular carcinoma with intra-atrial tumor thrombi. A report of three cases responsive to thalidomide treatment and literature review. Oncology. 2004; 67(3-4):320-6.

5. Koo JE, Kim JH, Lim YS, Park SJ, Won HJ, Sung KB, Suh DJ. Combination of transarterial chemoembolization and threedimensional conformal radiotherapy for hepatocellular carcinoma with inferior vena cava tumor thrombus. Int J Radiat Oncol Biol Phys. 2010;78(1):180-7.

6. Okuda K, Ohtsuki T, Obata H, Tomimatsu M, Okazaki N, Hasegawa H, Nakajima Y, Ohnishi K. Natural history of hepatocellular carcinoma and prognosis in relation to treatment. Study of 850 patients. Cancer. 1985;56(4): 918-28

7. Florman S, Weaver M, Primeaux P, Killackey M, Sierra R, Gomez S, Haque S, Regenstein F, Balart L. Aggressive resection of hepatocellular carcinoma with right atrial involvement. Am Surg. 2009;75(11):1104-8.

8. Lin HH, Hsieh CB, Chu HC, Chang WK, Chao YC, Hsieh TY. Acute pulmonary embolism as the first manifestation of hepatocellular carcinoma complicated with tumor thrombi in the inferior vena cava: surgery or not? Dig Dis Sci. 2007;52(6):1554-7.

9. Le Treut YP, Hardwigsen J, Ananian P, Saïsse J, Grégoire E, Richa H, Campan $P$. Resection of hepatocellular carcinoma with tumor thrombus in the major vasculature: a European case-control series. J Gastrointest Surg. 2006;10(6): 855-62.

10. Wu CC, Hseih S, Ho WM, Tang JS, Liu TJ, P'eng FK. Surgical treatment for recurrent hepatocellular carcinoma with tumour thrombi in right atrium: using cardiopulmonary bypass and deep hypothermic circulatory arrest. J Surg Oncol. 2000;74(3):227-31.

11. Ando E, Tanaka M, Yamashita F, Kuromatsu R, Yutani S, Fukumori K, Sumie S, Yano Y, Okuda K, Sata M. Hepatic arterial infusion chemotherapy for advanced hepatocellular carcinoma with portal vein tumor thrombosis: analysis of 48 cases. Cancer. 2002;95(3):588-95.

12. Hou JZ, Zeng ZC, Zhang JY, Fan J, Zhou J, Zeng MS. Influence of tumor thrombus location on the outcome of external-beam radiation therapy in advanced hepatocellular carcinoma with macrovascular invasion. Int J Radiat Oncol Biol Phys. 2012;84(2):362-8.

13. Bruix J, Sherman M. Management of hepatocellular carcinoma: an update. Hepatology. 2011;53(3):1020-2.

14. Xia T, Li H, Sun Q, Wang Y, Fan N, Yu Y, Li P, Chang JY. Promising clinica outcome of stereotactic body radiation therapy for patients with inoperable stage I/II non-small-cell lung cancer. Int J Radiat Oncol Biol Phys. 2006;66(1): $117-25$

15. Torre LA, Bray F, Siegel RL, Ferlay J, Lortet-Tieulent J, Jemal A. Global cancer statistics, 2012. CA Cancer J Clin. 2015;65(2):87-108.

16. Chen $W$, Zheng $R$, Baade PD, Zhang $S$, Zeng $H$, Bray F, Jemal $A$, Yu XQ, He J. Cancer statistics in China, 2015. CA Cancer J Clin. 2016;66(2):115-32.
17. Perz JF, Armstrong GL, Farrington LA, Hutin YJ, Bell BP. The contributions of hepatitis $B$ virus and hepatitis $C$ virus infections to cirrhosis and primary liver cancer worldwide. J Hepatol. 2006;45(4):529-38.

18. Ryder SD. Guidelines for the diagnosis and treatment of hepatocellular carcinoma (HCC) in adults. Gut. 2003;52(Suppl 3):iii1-8.

19. Schlachterman A, Craft WW Jr, Hilgenfeldt E, Mitra A, Cabrera R. Current and future treatments for hepatocellular carcinoma. World J Gastroenterol. 2015; 21(28):8478-91.

20. Kojiro M, Nakahara H, Sugihara S, Murakami T, Nakashima T, Kawasaki H. Hepatocellular carcinoma with intra-atrial tumor growth. A clinicopathologic study of 18 autopsy cases. Arch Pathol Lab Med. 1984;108(12):989-92.

21. Edmondson HA, Steiner PE. Primary carcinoma of the liver: a study of 100 cases among 48,900 necropsies. Cancer. 1954;7(3):462-503.

22. Gustafson EG. An analysis of 62 cases of primary carcinoma of the liver based on 24400 necropsies at Bellevue hospital. Ann Intern Med. 1937;11(6): 889-900.

23. Inoue $\mathrm{Y}$, Hayashi M, Katsumata T, Shibayama $\mathrm{Y}$, Tanigawa N. Hepatocellular carcinoma with right atrial tumor thrombus: report of a case. Surg Today. 2011;41(8):1122-9.

24. Okada S, Okazaki N, Nose H, Yoshimori M, Aoki K. Prognostic factors in patients with hepatocellular carcinoma receiving systemic chemotherapy. Hepatology. 1992:16(1):112-7.

25. Raoul JL, Guyader D, Bretagne JF, Duvauferrier R, Bourguet P, Bekhechi D, Deugnier YM, Gosselin M. Randomized controlled trial for hepatocellular carcinoma with portal vein thrombosis: intra-arterial iodine-131-iodized oil versus medical support. J Nucl Med. 1994;35(11):1782-7.

26. Akashi Y, Koreeda C, Enomoto S, Uchiyama S, Mizuno T, Shiozaki Y, Sameshima Y, Inoue K. Prognosis of unresectable hepatocellular carcinoma: an evaluation based on multivariate analysis of 90 cases. Hepatology. 1991; 14(2):262-8.

27. Wang $Y$, Yuan L, Ge RL, Sun Y, Wei G. Survival benefit of surgical treatment for hepatocellular carcinoma with inferior vena cava/right atrium tumor thrombus: results of a retrospective cohort study. Ann Surg Oncol. 2013; 20(3):914-22.

28. Li AJ, Zhou WP, Lin C, Lang XL, Wang ZG, Yang XY, Tang QH, Tao R, Wu MC. Surgical treatment of hepatocellular carcinoma with inferior vena cava tumor thrombus: a new classification for surgical guidance. Hepatobiliary Pancreat Dis Int. 2013;12(3):263-9.

29. Wakayama K, Kamiyama T, Yokoo H, Kakisaka T, Kamachi H, Tsuruga Y, Nakanishi K, Shimamura T, Todo S, Taketomi A. Surgical management of hepatocellular carcinoma with tumor thrombi in the inferior vena cava or right atrium. World J Surg Oncol. 2013;11:259.

30. Remouchamps VM, Vicini FA, Sharpe MB, Kestin LL, Martinez AA, Wong JW. Significant reductions in heart and lung doses using deep inspiration breath hold with active breathing control and intensity-modulated radiation therapy for patients treated with locoregional breast irradiation. Int J Radiat Oncol Biol Phys. 2003;55(22):392-406

31. Li Y, Lou J, Oiu S, Guo Y, Pan M. Stereotactic radiotherapy for the treatment of lung cancer with a giant left atrial tumor thrombus: a case report and literature review. Oncol Lett. 2016;11(3):2229-32.

32. Zeng ZC, Fan J, Tang ZY, Zhou J, Qin LX, Wang JH, Sun HC, Wang BL, Zhang JY, Jiang GL, et al. A comparison of treatment combinations with and without radiotherapy for hepatocellular carcinoma with portal vein and/or inferior vena cava tumor thrombus. Int J Radiat Oncol Biol Phys. 2005;61(2):432-43

33. Duan F, Yu W, Wang Y, Liu FY, Song P, Wang ZJ, Yan JY, Yuan K, Wang MQ. Trans-arterial chemoembolization and external beam radiation therapy for treatment of hepatocellular carcinoma with a tumor thrombus in the inferior vena cava and right atrium. Cancer Imaging. 2015;15:7.

\section{Publisher's Note}

Springer Nature remains neutral with regard to jurisdictional claims in published maps and institutional affiliations. 